University of Wollongong

Research Online

Faculty of Engineering - Papers (Archive)

Faculty of Engineering and Information

Sciences

$1-1-2013$

\title{
Effect of eccentric load on retrofitted reinforced concrete columns confined with FRP
}

Thong M. Pham

University Of Wollongong, tmp@uow.edu.au

X Lei

University of Wollongong, x1158@uowmail.edu.au

Muhammad N. S Hadi

University of Wollongong, mhadi@uow.edu.au

Follow this and additional works at: https://ro.uow.edu.au/engpapers

Part of the Engineering Commons

https://ro.uow.edu.au/engpapers/5247

\section{Recommended Citation}

Pham, Thong M.; Lei, X; and Hadi, Muhammad N. S: Effect of eccentric load on retrofitted reinforced concrete columns confined with FRP 2013, 139-144.

https://ro.uow.edu.au/engpapers/5247

Research Online is the open access institutional repository for the University of Wollongong. For further information contact the UOW Library: research-pubs@uow.edu.au 


\title{
Effect of eccentric load on retrofitted reinforced concrete columns confined with FRP
}

\author{
T.M. Pham, X. Lei \& M.N.S. Hadi \\ School of Civil, Mining and Environmental Engineering, University of Wollongong, Wollongong, NSW, Australia
}

\begin{abstract}
Different behaviour of diverse sections of confined Reinforced Concrete (RC) columns under eccentric load is investigated in this study. Three types of sections are considered, which include square columns, square with rounded corners and modified circular columns. Twelve reinforced square concrete columns were made from normal strength concrete and subdivided into four groups. The first three columns were the Reference Group and had no modification. The next three columns were modified with round corners and wrapped with three layers of Carbon Fibre Reinforced Polymer (CFRP), another three were bonded with four pieces of segmental circular concrete covers and wrapped with three layers of CFRP, and the last three were bonded with concrete covers and confined with steel straps. All columns were tested under concentric loading, $15 \mathrm{~mm}$ and $25 \mathrm{~mm}$ eccentric loading. Results from the study show that all confinement methods increase capacity and ductility of columns, in which segmental circular concrete covers considerably reduce the stress concentration on the corners and increase the efficiency of the confinement. Effect of eccentric load on the specimens wrapped with FRP is significantly higher than the Reference Group.
\end{abstract}

\section{INTRODUCTION}

Most of the existing columns are square or rectangular in cross section. Early research studies indicate that FRP-confined square or rectangular columns with sharp corners provide little enhancement on their load-carrying capacity (Wu \& Zhou 2010). Some investigations on FRP strengthened reinforced concrete (RC) columns under concentric load (Kumutha et al. 2007; Ilki et al. 2008) have been reported. Furthermore, RC columns under eccentric load were tested to study the combination of compression and bending behaviour ( $\mathrm{Li} \&$ Hadi 2003; Hadi \& Li 2004; Hadi 2006a; Hadi 2006b; Hadi 2007a; Hadi 2007b). These studies concluded that the use of FRP increases the capacity of columns. Following the same direction, this study focuses on retrofitting structural members by comparing three different approaches of strengthening.

There are cases where structures need to be retrofitted, for example, change of the use of the structures, change of design codes or construction errors. As most structures are built using normal strength concrete, the experiments of this study use normal strength concrete. This study investigates a technique of changing the cross section of a RC column from a square to a circle. After changing the cross section from a square to a circle, two wrapping materials were investigated: CFRP and steel straps. Behaviour of columns of different cross sections is investigated as well.

\section{EXPERIMENTAL PROGRAMME}

The experimental programme was carried out at the High Bay Civil Engineering Laboratory at the University of Wollongong. All materials were purchased from local suppliers and then prepared in the laboratory.

\subsection{Design of experiments}

A total of twelve square reinforced concrete columns were cast. The dimensions of the columns were $150 \mathrm{~mm}$ by $150 \mathrm{~mm}$ in cross-section and $800 \mathrm{~mm}$ in height.

The columns were categorised into four groups and each group consisted of three specimens simulating a specific technique of strengthening. Group $\mathrm{N}$ was used as a reference group with no external strengthening and no modification. Group RF columns were cast to leave $20 \mathrm{~mm}$ round corners then wrapped with three layers of CFRP. Group CF and CS simulate a new type of strengthening method. All columns in Groups $\mathrm{CF}$ and Group CS were bonded with four pieces of circular segments which were made from concrete of the same strength as column concrete to modify the shape of cross-section from square to circular using epoxy resin. This process is called here circularisation of cross-section. After the circularisation, columns in Group CF were wrapped with three layers of CFRP and columns in Group CS were bonded with steel straps at $30 \mathrm{~mm}$ spacing. The required steel straps and CFRP were estimated based on ACI 440.2R-02 (2002) and 
Table 1. Test matrix.

Internal External

Specimen Modification Reinforcement Reinforcement Eccentricity

\begin{tabular}{llllr}
\hline N-0 & \multirow{2}{*}{ None } & 4N12 & None & 0 \\
N-15 & & R6@120 & & 15 \\
N-25 & & & & 25 \\
RF-0 & 20mm & 4N12 & Three layers & 0 \\
RF-15 & Round & R6@120 & of CFRP & 15 \\
RF-25 & Corners & & & 25 \\
CF-0 & Concrete & 4N12 & Three layers & 0 \\
CF-15 & Covers & R6@120 & of CFRP & 15 \\
CF-25 & & & & 25 \\
CS-0 & Concrete & 4N12 & Steel & 0 \\
CS-15 & Covers & R6@120 & Straps & 15 \\
CS-25 & & & & 25 \\
\hline
\end{tabular}
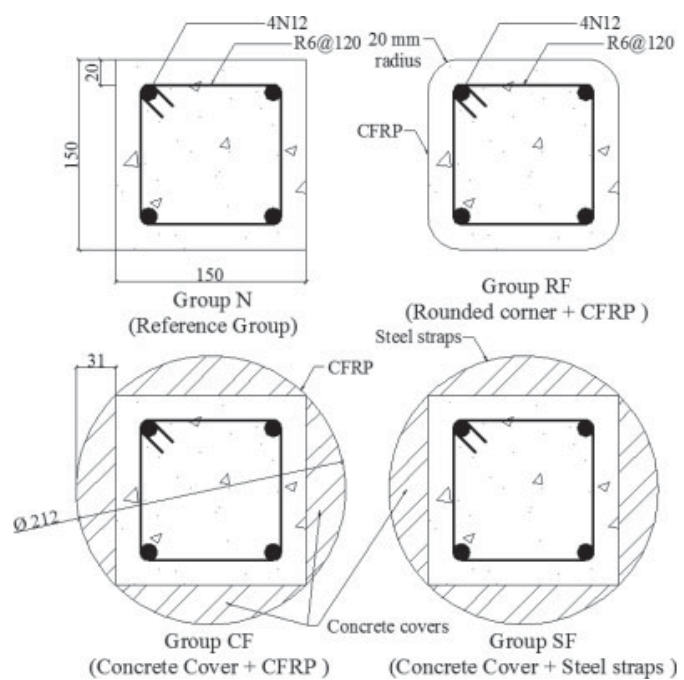

Figure 1. Cross section view of specimens (all units in $\mathrm{mm}$ ).

ACI 440.2R-08 (2008), respectively. From each group, one column was concentrically loaded, while the second and the third columns were subjected to eccentric loading of $15 \mathrm{~mm}$ and $25 \mathrm{~mm}$ eccentricity, respectively. Table 1 depicts the configuration of the experiment and Figure 1 shows the cross section view of the specimens.

The notation of the specimens consists of two parts: the first part is N-, RF-, CF- and CS-stating the name of the group to which the specimens belong (Normal, Round corners with FRP, Circular with FRP and Circular with Steel straps). The second part indicates the loading condition. For instant, 0 means concentric load, 15 and 25 mean loading at 15 and $25 \mathrm{~mm}$ eccentricity, respectively.

\subsection{Design of columns}

Normal strength concrete was used with nominal compressive strength of $32 \mathrm{MPa} .20 \mathrm{~mm}$ concrete cover was maintained. The reinforcement was designed in accordance with AS 3600 (2009) simulating columns with which structures need to be strengthened.

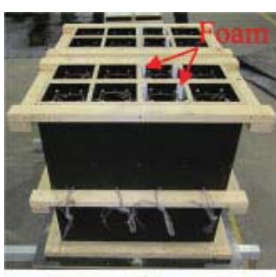

(a)

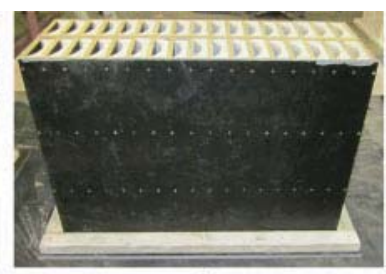

(b)
Figure 2. Formworks: (a) Columns (b) Concrete covers.

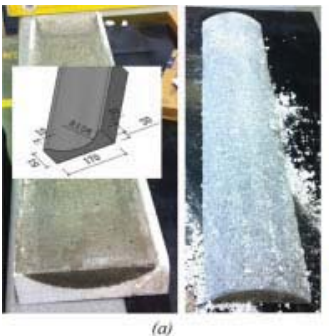

Figure 3. (a) Concrete covers (b) Specimens bonded.
The reinforcement was identical for all columns in all groups. Four N12 bars (12 mm deformed bars with $500 \mathrm{MPa}$ nominal tensile strength) were the longitudinal reinforcement and R6 bars $(6 \mathrm{~mm}$ plain bars with $250 \mathrm{MPa}$ nominal tensile strength) were provided as transverse reinforcement with $120 \mathrm{~mm}$ spacing.

\subsection{Casting of columns}

The concrete used in the experiments was ready-mixed concrete purchased from a local supplier, and was poured into two formworks when arrived. The first one was made for the columns and the second for the circular segments. All formworks were made from plywood and were screwed together with timber. Specially shaped foam was glued to the formworks in order to generate round corners for Group RF and also the circular segments for Group CF and CS. The details of the formworks are given in Figure 2.

\subsection{Bonding of concrete covers}

The concrete covers used for Groups CF and CS were removed from the formwork after 28 days. The foam on the concrete covers was firstly removed and the surface of the covers was ground using an electric grinder to ensure smooth contact when bonding with FRP. After the concrete covers and the surface of original columns were cleaned, the covers were bonded to the columns using epoxy resin which was mixed with $15 \%$ thickener (see Figure 3). The columns were then left to dry for 14 days as specified by the suppliers.

\subsection{External reinforcement of columns}

Before wrapping with FRP, the surface of the columns was cleaned by water and left to dry. The adhesive 
was a mixture of epoxy resin and hardener at 5:1 ratio. Before the first layer of CFRP was attached, adhesive was spread onto the surface of the column, and then CFRP was attached onto the surface. After the first ring, adhesive was spread onto the surface of the first layer of CFRP and the second layer was bonded. The same procedure was followed until three layers of CFRP were bonded continuously on the surface. The main fibre orientation was perpendicular to the longitudinal axis of the column. For each ring, $100 \mathrm{~mm}$ overlap was maintained. All the FRP confined specimens were cured in room temperature at the laboratory for seven days.

\subsection{Preliminary tests}

The average compressive strength of concrete at 28 days was $27 \mathrm{MPa}$. Properties of CFRP were determined by FRP coupon tests which were conducted in accordance with ASTM D7565 (2010). Three coupons were made with a width of $25 \mathrm{~mm}$. Each coupon was made of three individual layers of CFRP and bonded with epoxy resin. The coupons were capped at both ends and a gauge length of a least $150 \mathrm{~mm}$ was maintained. The actual width and thickness were measured before the tensile tests and the ultimate tensile load and displacement were recorded during the tests. The average width of the tests coupon was $28 \mathrm{~mm}$, and the average maximum tensile force per unit width was $1972 \mathrm{~N} / \mathrm{mm}$. The strain at the average maximum tensile force and the average elastic modulus were $0.024 \mathrm{~mm} / \mathrm{mm}$ and $82 \mathrm{kN} / \mathrm{mm}$, respectively.

Coupon tests for reinforcing steels and steel straps were also conducted. Three specimens of N12 deformed bars and R6 plain bars with $250 \mathrm{~mm}$ in length were prepared and tested according to AS 1391 (2007). Three coupons of steel straps which were used in confining columns in Group CS were prepared and tested according to ASTM D3953 (2007). The ultimate tensile strength for N12 deformed bars was $568 \mathrm{MPa}$, for R6 plain bars, $477 \mathrm{MPa}$ and for steel straps, $598 \mathrm{MPa}$.

\subsection{Column testing}

All columns were tested using the $5000 \mathrm{kN}$ Denison compression testing machine. The eccentricity was achieved by a special loading head with gauges located 15 and $25 \mathrm{~mm}$ off centre. The loading head was paired with a steel plate with overhang edge, as shown in Figure 4.

The columns were capped with high strength plaster at both ends to ensure full contact between the loading head and the column before putting the columns on the testing machine. Calibration was then carried out to ensure that the columns were placed at the centre of the testing machine.

In order to measure the lateral displacement for the eccentrically loaded columns, a laser LVDT was used and connected to the data-logger as well (see Figure 4a). The laser LVDT was set at the mid-height

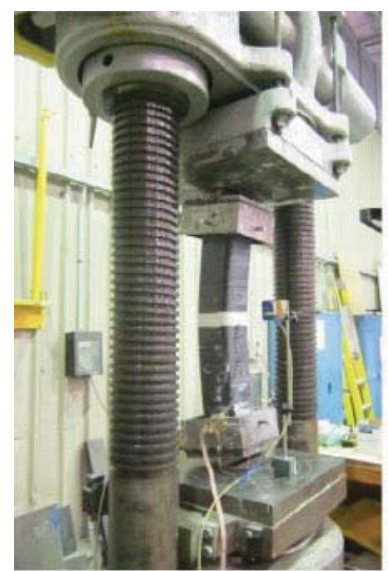

(a)

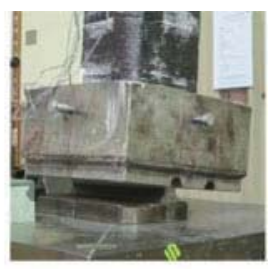

(b)

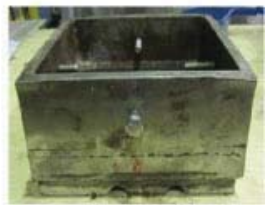

(c)
Figure 4. (a) Loading system (b) Loading head and overhang edges (c) Loading head.

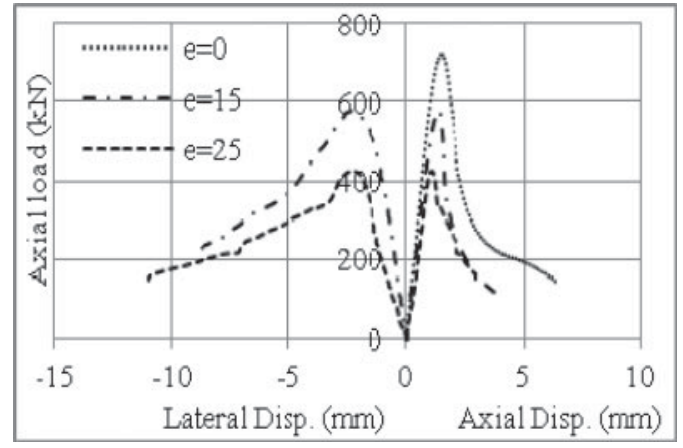

Figure 5. Load - displacement diagram (Group N).

of the column. All the tests were displacement controlled. For compression tests, the loading rate was set at $0.5 \mathrm{~mm} / \mathrm{min}$.

\section{RESULTS AND DISCUSSION}

All specimens were tested to failure. The results of every group are presented to study different behaviour of specimens under different loading schemes.

\subsection{Behaviour of group $N$}

Specimens N-0, N-15 and N-25 failed by concrete spalling on the surface and buckling of the longitudinal reinforcement while Specimen N-F failed by de-bonding of concrete and longitudinal steels at the ends. The same trend of the axial load - displacement diagram of three columns in Group N was observed. The value of axial load of the specimens in this group increases to the peak load, and then decreases rapidly until failure (see Figure 5). 


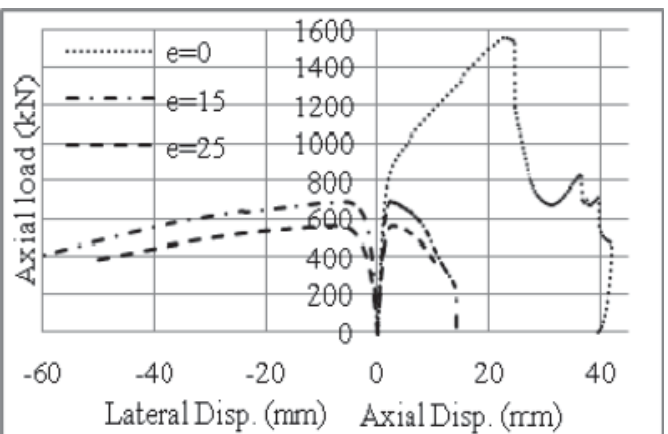

Figure 6. Load - displacement diagram (Group RF).

\subsection{Behaviour of group $R F$}

Specimen RF-0 failed by concrete crushing and FRP ruptured. Specimen RF-15 failed by concrete crushing in the compressive region while cracking of the specimen in the tension region was observed between two rings of CFRP at the mid-height. Specimen RF25 failed by the same behaviour as Specimen RF-15 except the rupture of the longitudinal steels in the tension region led to complete collapse of the specimen. However, no CFRP rupture was recorded in both cases above, which indicates that the specimens did not fully utilise the FRP confinement.

The axial load of Specimen RF-0 kept increasing to $1542 \mathrm{kN}$, after which a loud cracking sound can be heard when one ring of CFRP ruptured, then the load immediately dropped to $1194 \mathrm{kN}$. Subsequently, a small part of a CFRP ring ruptured which led to slow decrease of compressive load. The axial load of Specimens RF-15 and RF-25 increases linearly to the peak load and then decreases until failure while the axial load of Specimen RF-0 increases to the yield load and keeps rising to the peak load with another slope of the axial load - displacement curve (see Figure 6).

\subsection{Behaviour of group $C F$}

The columns of Group CF failed by rupture of FRP at mid-height and concrete crushed in the compressive region (see Figure 7a). For Specimens CF-15 and $\mathrm{CF}-25$, cracks were observed in the tension region at the early stage.

All specimens reached the peak load and then decreased significantly due to rupture of FRP rings which created a loud sound. Take Specimen CF-25 as a typical example: the specimen reached a peak load of $1124 \mathrm{kN}$, then a small cracking sound was heard and the applied load decreased to $1082 \mathrm{kN}$. Consequently, some continuously small cracking sound and a loud sound were recorded at which time the applied load of the specimen dropped to $386 \mathrm{kN}(64 \%)$. The same trend of axial load - displacement diagram was observed with Group RF, in which the axial load of Specimens CF-15 and CF-25 increases linearly to the peak load and then decreases until failure while the axial load of Specimen CF-0 increases sharply to

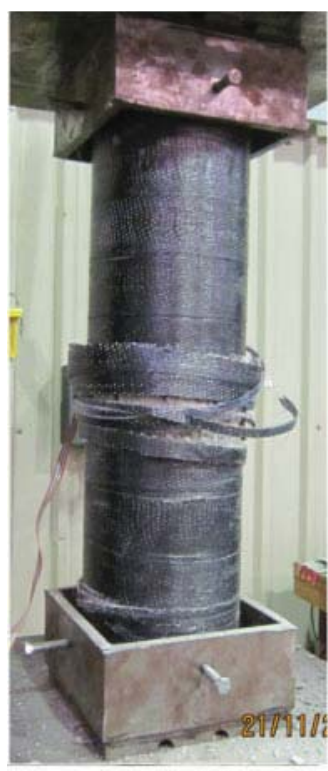

(b) $\mathrm{CF}-0$

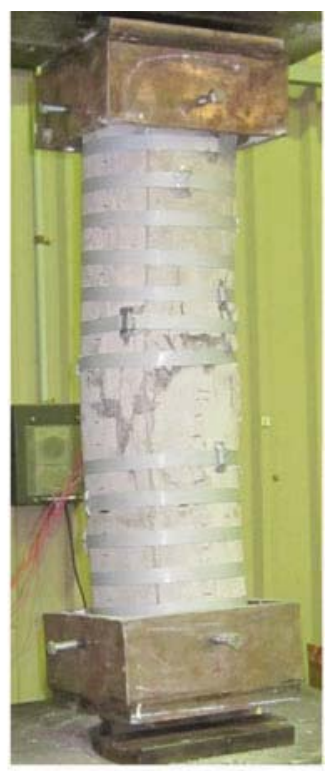

(a) $\mathrm{CS}-15$
Figure 7. Failure modes of Columns CF-0 and CS-15.

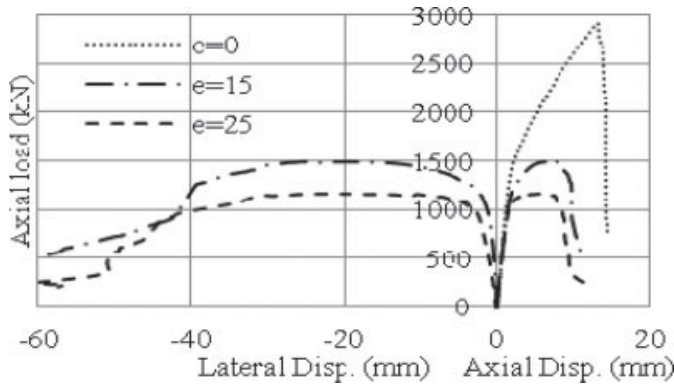

Figure 8. Load - displacement diagram (Group CF).

the yield load and keeps increasing to the peak load with another slope of the axial load - displacement diagram (see Figure 8).

\subsection{Behaviour of group CS}

The specimens of Group CS failed by rupture of steel straps at mid-height and concrete crushed in the compressive region (see Figure $7 \mathrm{~b}$ ). The axial load of all specimens of this group increases the peak load and then decreases significantly to failure. The axial loaddisplacement diagrams of columns of this group are plotted in Figure 9.

\subsection{Increase of column capacity}

Table 2 shows the capacity of all columns tested in this study. The experimental results depict that the capacity of the columns of Group CF is the highest, followed by the columns of Groups RF and CS, respectively. For columns wrapped with CFRP, the increase of columns 


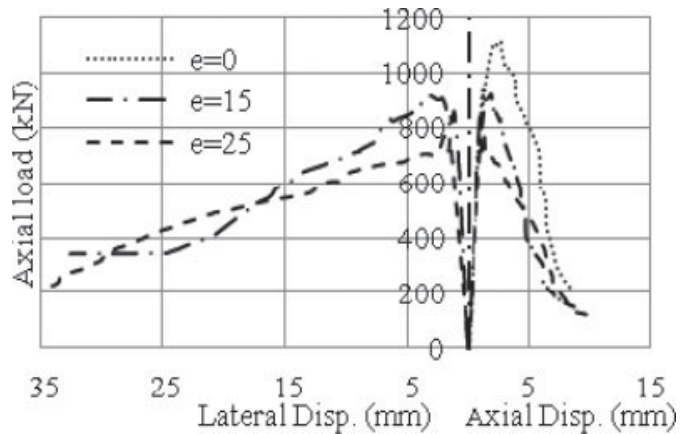

Figure 9. Load - displacement diagram (Group CS).

Table 2. Summary of column capacity.

\begin{tabular}{lll}
\hline Column & $\begin{array}{l}\text { Maximum axial } \\
\text { load }(\mathrm{kN})\end{array}$ & $\begin{array}{l}\text { Normalised } \\
\text { max load* }\end{array}$ \\
\hline N0 & 724 & 1 \\
N15 & 579 & 1 \\
N25 & 427 & 1 \\
RF0 & 1562 & 2.16 \\
RF15 & 686 & 1.18 \\
RF25 & 562 & 1.32 \\
CF0 & 2907 & 4.02 \\
CF15 & 1490 & 2.57 \\
CF25 & 1171 & 2.74 \\
CS0 & 1116 & 1.54 \\
CS15 & 917 & 1.58 \\
CS25 & 766 & 1.79 \\
\hline
\end{tabular}

*The maximum axial load of each column is compared to the corresponding specimens in Group N.

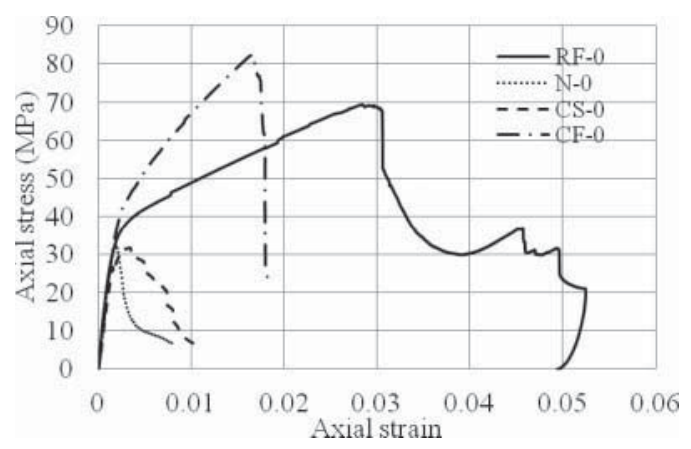

Figure 10. Axial stress - strain diagram.

capacity under concentric load is $50 \%$ higher than those under eccentric load.

The nominal average axial stress of the specimens under concentric load was calculated by dividing the axial load by the cross section area of the specimens. The axial stress - strain curves are presented in Fig. 10. The slope of the post-peak curve of Specimen CF-0 is higher than that of Specimen RF-0. Thus, it can be seen that the most effective confinement occurred in Specimen CF-0, followed by Specimen RF-0.

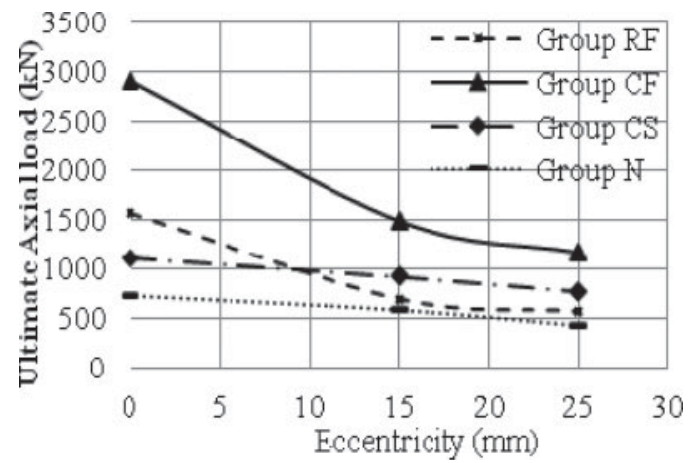

Figure 11. Ultimate axial load - eccentricity diagram.

\subsection{Effect of eccentricity}

In order to investigate the effect of the eccentricity, the ultimate axial load - eccentricity diagram is presented in Figure 11. The shapes of Group N and Group CS are comparable, which are linear. In addition, the similar curves of this diagram can be seen in Groups RF and $\mathrm{CF}$, which is quadratic. Figure 10 shows that the capacity of columns in Groups RF and CF drops faster than Groups N and CS when eccentricity is applied. The capacity of Specimens RF-25 and CF-25 equal to about $37 \%$ of Specimens RF- 0 and CF- 0 , respectively, while the corresponding number of Groups $\mathrm{N}$ and CS is $65 \%$ approximately.

\section{CONCLUSIONS}

From the experimental testing, the following conclusions can be drawn.

Bonding segmental circular concrete covers to change the section of columns from square to circular, then wrapping with FRP outperforms the capacity of the columns retrofitted using the two other techniques.

Effect of eccentricity on FRP confined RC columns is significantly higher than unconfined RC columns.

CFRP is recommended for columns subjected to concentric load as well as eccentric load.

\section{REFERENCES}

ACI 440.2R-02 (2002), Guide for the Design and Construction of Externally Bonded FRP Systems for Strengthening Concrete Structures, American Concrete Institute.

ACI 440.2R-08 (2008), Guide for the Design and Construction of Externally Bonded FRP Systems for Strengthening Concrete Structures, American Concrete Institute.

AS 1391. (2007). Metallic Materials-Tensile Testing at Ambient Temperature. Australian Standard 1391:2007. SAI Global database.

AS 3600. (2009). Concrete Structures. Australian Standard 3600:2009. SAI Global database.

ASTM D3953. (2007). Standard Speci?cation for Strapping, Flat Steel and Seals. ASTM D3953:2007. ASTM Database. 
ASTM D7565. (2010). Standard test methods for determining tensile properties of fibre reinforced polymer matrix composites used for strengthening civil structures. ASTM D7565:2010. ASTM Database.

Hadi, M.N.S. (2006a). "Behaviour of FRP wrapped normal strength concrete columns under eccentric loading." Composite Structures 72(4): 503-511.

Hadi, M.N.S. (2006b). "Comparative study of eccentrically loaded FRP wrapped columns." Composite Structures 74(2): 127-135.

Hadi, M.N.S. (2007a). "Behaviour of FRP strengthened concrete columns under eccentric compression loading." Composite Structures 77(1): 92-96.

Hadi, M.N.S. (2007b). "The behaviour of FRP wrapped HSC columns under different eccentric loads." Composite Structures 78(4): 560-566.

Hadi, M.N.S. and Li, J. (2004). "External reinforcement of high strength concrete columns." Composite Structures 65(3-4): 279-287.
Ilki, A., Peker, O., Karamuk, E., Demir, C. and Kumbasar, N. (2008). "FRP retrofit of low and medium strength circular and rectangular reinforced concrete columns." Journal of Materials in Civil Engineering 20(2): 169-188.

Kumutha, R., Vaidyanathan, R. and Palanichamy, M.S. (2007). "Behaviour of reinforced concrete rectangular columns strengthened using GFRP." Cement \& Concrete Composites 29(8): 609-615.

Li, J. and Hadi, M.N.S. (2003). "Behaviour of externally confined high-strength concrete columns under eccentric loading." Composite Structures 62(2): 145-153.

Wu, Y.F. and Zhou, Y.W. (2010). "Unified Strength Model Based on Hoek-Brown Failure Criterion for Circular and Square Concrete Columns Confined by FRP." Journal of Composites for Construction 14(2): 175-184. 